\title{
Design of bionic mole forelimb intelligent row cleaners
}

\author{
Honglei Jia ${ }^{1,2}$, Qi Wang ${ }^{1,2}$, Dongyan Huang ${ }^{1,2^{*}}$, Longtu Zhu ${ }^{1,2}$, Mingwei $\mathrm{Li}^{1,2}$, Jiale Zhao ${ }^{1,2}$ \\ (1. School of Biological and Agricultural Engineering, Jilin University, Changchun 130022, China; \\ 2. Key Laboratory of Bionic Engineering, Ministry of Education, Jilin University, Changchun 130022, China)
}

\begin{abstract}
In Northeast China under no-till conditions the amount of maize stubble of the previous year's crop severely limit the quality of sowing operations by unstable operating depth of normal planter row cleaners. Thus, in this study, bionic mole forelimb intelligent row cleaners comprising of a cleaning device and a depth intelligent control system were designed. Via theoretical analysis, computer-based simulation, and test optimized design, the mechanism of bionic cleaners that possessed the forelimb motion morphology and the front claw toe structural morphology of moles was studied, the effects of structural parameters of bionic cleaners on the cleaning quality were clarified. Based on a pressure sensor, a depth intelligent control system was designed, which enhanced the depth stability of the cleaning devices. The types of bionic cleaners were identified by simulation on EDEM software. Then regression equations between different parameters and operation evaluation indices were established, and the optimal parameter combination was identified on Design-Expert software with a rotation radius of $150 \mathrm{~mm}$ and a motion deflection angle of $15.8^{\circ}$, at which the cleaning rate was $91.3 \%$. Field tests under the optimal parameter combination showed that bionic cleaners outperformed normal planar cleaners, and the depth intelligent control system could efficiently improve the performance of the row cleaners. The straw cleaning rate of the bionic mole forelimb intelligent row cleaners under total straw mulching fields was $90.9 \%$, which was $21.3 \%$ higher than that of normal cleaners, and the ground surfaces after operation satisfied the agricultural requirements of maize no-tillage sowing.
\end{abstract}

Keywords: bionic mole forelimb, intelligent row cleaners, intelligent control systems, no-till sowing, corn production, residue management

DOI: $10.25165 /$ j.ijabe.20191203.4408

Citation: Jia H L, Wang Q, Huang D Y, Zhu L T, Li M W, Zhao J L. Design of bionic mole forelimb intelligent row cleaners. Int J Agric \& Biol Eng, 2019; 12(3): 27-35.

\section{Introduction}

The no-tillage planting as an advanced farming technique is capable of preventing soil erosion, improving soil organic matter, structure and crop growing time $e^{[1-4]}$. This technique has been extensively applying in Northeast China in recent years. However, the drying climate and long cycle maize varieties make maize stubble thick and hard to rotten in the region ${ }^{[5,6]}$. During springtime, due to the amount of stubble and uneven distribution in the field, the straw cleaning rate and the width stability of the row cleaners is poor, which would negatively affect seeds germination and yield ${ }^{[7-9]}$. Thus, row cleaners are the basis that ensures the high operational quality of the no-tillage mulching planting mode.

At present, row cleaners are classified according to their working mechanism into active and passive type ${ }^{[10]}$. In particular, the passive row cleaner is widely applied because of its advantages of the small soil disturbance, high humid reserving effect and low operational resistance soil conditions ${ }^{[11]}$. Raoufat et al. ${ }^{[12,13]}$ designed a number of wheel-type free rotating row cleaner units

Received date: 2018-07-05 Accepted date: 2019-04-09

Biographies: Honglei Jia, PhD, Professor, research interests: bionic intelligent agricultural machinery and conservation tillage technology, Email: jiahl@vip.163.com; Qi Wang, PhD candidate, research interests: bionic intelligent agricultural machinery, Email: wangqi_4034@163.com; Longtu Zhu, PhD candidate, research interests: intelligent agricultural machinery design, Email: zhult17@mails.jlu.edu.cn; Mingwei Li, PhD candidate, research interests: intelligent agricultural machinery design, Email: lmw271314@163.com; Jiale Zhao, PhD, Associate Professor, research interests: conservation tillage technology and agricultural mechanization, Email: zhaojiale0313@163.com.

*Corresponding author: Dongyan Huang, $\mathrm{PhD}$, Professor, research interests: intelligent agricultural machinery. Mailing address: School of Biological and Agricultural Engineering, Jilin University, Changchun 130022, China. Tel: +86-13610712601, Fax: +86-431-85095760; Email: cchdy760829@sina.com. consisting of two meshed wheels, the straw cleaning rate of the row cleaner for the wheat half-residue and whole-residue plots was $45 \%$ and $70 \%$, respectively, and the row cleaners worked more effectively at high residue conditions. Fan et al. ${ }^{[14]}$ designed a Finger-type Anti-blocking row cleaner, and the test results showed that it had a good performance when the average straw coverage was $75.15 \%$, and the residue removal averaged $62.7 \%$. Lin et al. ${ }^{[15]}$ designed a rolling disc-like row cleaner with Archimedes spiral blade which was suitable for the Northeast ridge patterns of conservation tillage, it could effectively clean the residues on ridges and provided a favorable working environment for sowing units. The above mentioned row cleaners have good working performance when worked in the less-residue plots and on ridges, however, they are not suitable for the corn whole-residue plots in northeast China, so as to the row cleaners installed on no-till planters used in the region currently.

Bionics, as an emerging discipline, has been widely applied in agriculture engineering ${ }^{[16]}$. Moles are small hole residing animals that had extremely high excavation efficiency. Liu[ ${ }^{17]}$ reported that the mole claw toes have high cutting mechanical performance and small cutting resistance during excavation. Scott et al. ${ }^{[18]}$ found the included angle $\theta$ between the humerus and scapula enhanced the excavation and soil throwing efficiency of moles. Thus, the included angle $\theta$ of mole forelimbs, and the geometric characteristics of toes could be used to optimize normal planar cleaners.

In this study, in order to solve the mentioned problems and to improve the row cleaning performance in Northeast China, a bionic mole forelimb intelligent row cleaning device was designed based on engineering bionics and intelligent control technology. The bionic cleaners were designed by the structure-motion coupling bionics with mole forelimbs as the bionic prototype. On this basis, 
the straw cleaning mechanism was analyzed, and the effects of structural parameters on the cleaning quality was studied by the discrete element software EDEM. Then a depth intelligent control system was designed. The field experiment results showed that the control system was capable to control working depth in real-time, and the bionic mole forelimb intelligent row cleaning device has excellent straw cleaning performance, which can meet the requirements of operation in the corn whole-residue plots in Northeast China.

\section{Materials and methods}

\subsection{Design of bionic mole forelimb intelligent row cleaners}

2.1.1 Structure and working principle of bionic mole forelimb intelligent row cleaners

The structure of the bionic mole forelimb intelligent row cleaning device is showed in Figure 1. It consists of a bionic cleaning device and a depth intelligent control system. The bionic cleaning device consists of bionic cleaners, an assembled frame, a bearing seat, and depth-limited adjustment plate. The depth adjustment plate was installed on the frame with a bolt hinge, while the bearing seat was bolted at the positioning hole at the anterior of the installation frame. The bionic cleaners were fixed with circularly distributed bolts of the bearing seat. The depth intelligent control system consists of a depth-regulating device, control module and pneumatic transmission actuator. The depth-regulating device consists of an S-shaped pressure sensor, an air spring, a connection chamber, and rod end bearings, which two ends were attached with the no-tillage sowing unit and the installation frame, respectively. The control module and the pneumatic transmission actuator were installed in a metal box which was attached to the hanger of a no-tillage planter.
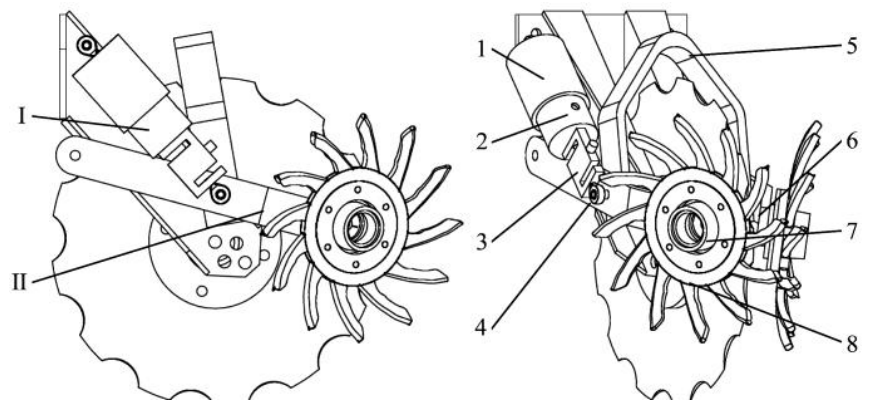

I. Depth regulating device $\quad$ II. Bionic cleaning device

1. Air spring 2. Connection chamber 3. S-shaped pressure sensor 4. Rod end bearing 5 . Installation frame 6. Depth-limited adjustment plates 7. Bearing seat 8 . Bionic cleaners

Figure 1 The structure of the bionic mole forelimb intelligent row cleaner

The bionic mole forelimb intelligent row cleaner was installed at the right front of the sowing unit (Figure 2). Prior to operation, the initial working depth of the bionic cleaning device was set by the depth adjusting plate. The pressure of the air spring was adjusted through the pneumatic transmission actuator, providing a downforce for the bionic cleaning device. Under the gravity and the downforce, the bionic cleaner could be inserted into the straw layer to contact with the soil layer at the preset depth. During the operation, due to the surface of the soil covered by straw residues and the varying soil density at different points, the operating depths of the bionic cleaning device could not be maintained consistent, thereby leading to change of pressure value detected from the S-shaped pressure sensor. Thus, the operational depth of the bionic cleaning device could be detected by real-time monitoring the pressures from the S-shaped pressure sensor. When the operating depths was smaller than the preset value, the control module would calculate the output regulation signals according to the difference between the current sensor-outputted signal and the preset depths. Therefore, the regulation signals could act on the electric-pneumatic regulator to enlarge the pressure of the air spring enlarging the downforce up to the consistency of the operation depths. During the operation, the bionic cleaners, under the joint action of machinery pull and soil counterforce would revolve around the shaft, picking up the beneath straw residues and throwing laterally rearward clearing out strip-like sowing zone for the sowing unit.

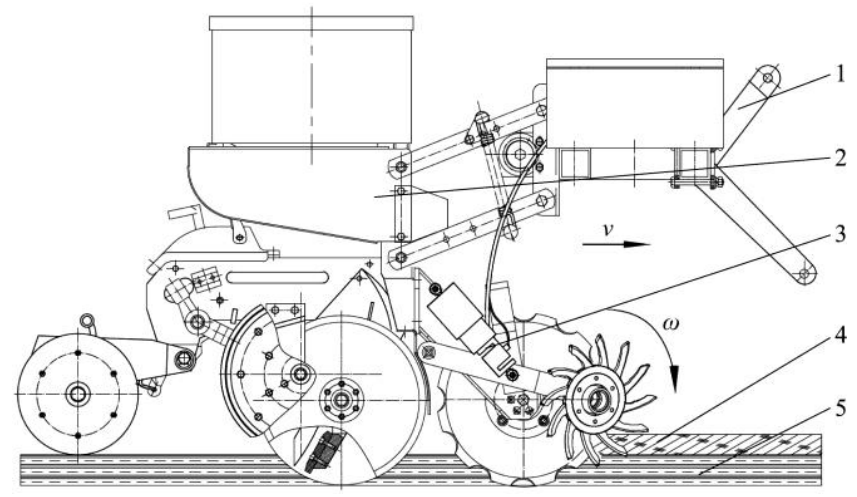

1. Frame 2. Seeder monomer 3. Bionic mole forelimb intelligent row cleaner 4. Straw residue layer 5. Soil layer

Figure 2 Working principle of bionic mole forelimb intelligent row cleaner

\subsubsection{Design of bionic cleaner}

The bionic cleaners were designed based on the mole forelimbs as a prototype. The circumference of the bionic cleaner was evenly distributed with 12 bionic fingers which simulating with the outline curves of the mole front claw toes. The fingers were designed by simulating the morphology of the mole forelimb motion function and formed a bionic included angle $\theta$ with the rotary table plane (Figure 3).

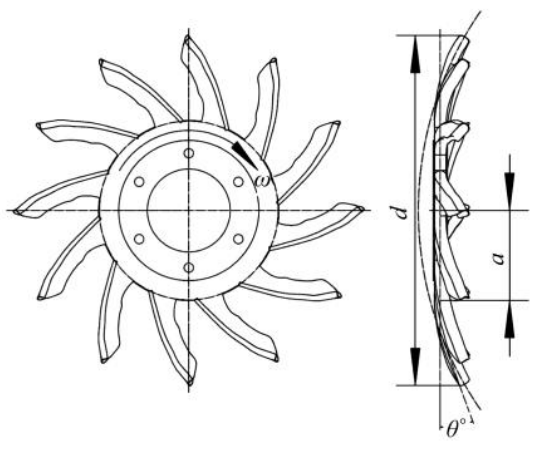

Figure 3 Sketch map of bionic cleaner

(1) Design of bionic fingers

The contour curves of the front claw toes showed excellent mechanical functions. The bionic fingers were designed by selecting the most representative contour curves $\left[{ }^{19]}\right.$. The structures of the fingers and the selected contour curve fitting equations are showed in Figure 4.

(2) Bionic included angle $\theta$

The humerus and bladebone of moles formed an included angle $\theta$ at the excavating direction ${ }^{[18]}$ (Figure 5). Therefore, the contact stroke of the front claw toes with the lateral hole walls during one excavation was very long, and excavation occurred at the hole wall height direction, and the overlap depth of two adjacent excavation orbits was small, which enhanced the 
excavation and soil lateral rearward throwing efficiency and weakened the excavation resistance.

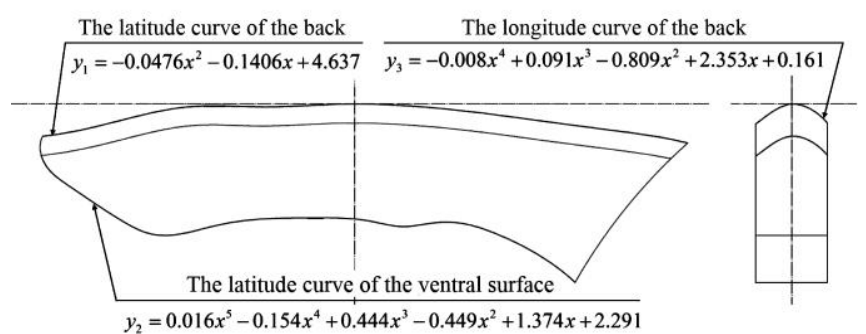

Figure 4 Structures of the fingers of bionic cleaner
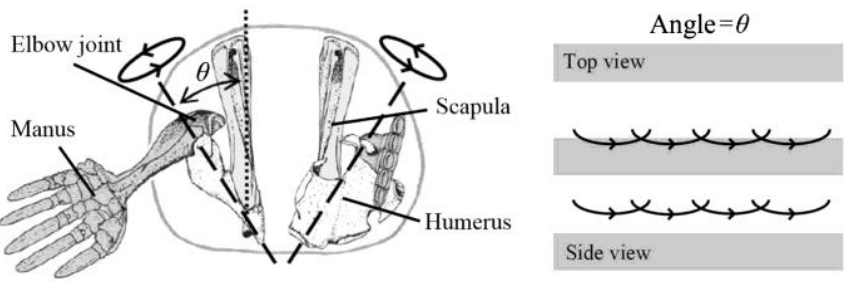

Figure 5 Sketch map of mole forelimb movement morphology and orbit

In the field, the fingers of row cleaner were in contact with the soil. Torque produced by traction and soil resistance rotated the row cleaner.

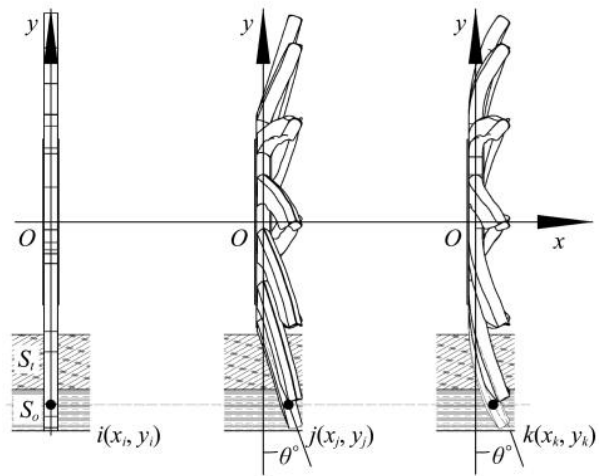

Note: $S_{t}$ is the straw residue layer; $S_{o}$ is the soil layer.

Figure 6 Analysis of torque for different cleaners

As shown in Figure 6, the force at the point of $i$ on the flat structure can be expressed by Equation (1).

$$
F_{i}=\mu N_{i}+\mu^{\prime} N_{i}^{\prime} S^{\prime}
$$

where, $F_{i}$ is the slip resistance of soil applied to the working surface at point $i ; \mu$ is the friction coefficient of soil to material; $N_{i}$ is the normal load acted on the working surface at point $i ; \mu^{\prime}$ is the adhesion coefficient; $N_{i}^{\prime}$ is the normal generated by water film adsorption at point $i ; S^{\prime}$ is the Area of capillary film.

The torque generated by the force at the point $i$ can be expressed by Equation (2).

$$
T_{i}=F_{i} \cdot L_{i}
$$

where, $T_{i}$ is the torque generated by the force at the point $i ; L$ is the arm.

Therefore, the torques generated by the force at the point $j$ and point $k$ of the cleaners with the bionic angle $\theta$ can be expressed by Equation (3).

$$
\begin{aligned}
& T_{i}=F_{i} \cdot L_{i}=F_{i} \cdot y_{i} \\
& T_{j}=F_{j} \cdot L_{j}=F_{j} \cdot \sqrt{x_{j}^{2}+y_{j}^{2}} \\
& T_{k}=F_{k} \cdot L_{k}=F_{k} \cdot \sqrt{x_{k}^{2}+y_{k}^{2}}
\end{aligned}
$$

From Equation (1), $F_{i}=F_{j}=F_{k}$ can be obtained from $y_{i}=y_{j}=y_{k}$. According to Equation (2) (3), $T_{j}>T_{i}, T_{k}>T_{i}$. The torque generated by the bionic cleaners is greater than that of flat cleaner.
The anterior claw of the bionic structure could generate a higher rotation torque to the cleaners, and provide larger throwing force to the working surface of the cleaner.

Therefore, when the bionic cleaner was working, fingers successively cut into the residue layer and the soil layer at an included angle $\theta$ with the ground. After the bionic cleaner revolved for one circle, the orbit of a single finger in the effective working zone of the cleaner plane was projected to be an arc, forming a fan-shaped working zone, shown as direction A in Figure 7. Due to the existence of the included angle $\theta$, the trajectory of the finger passing the plane of horizontal diameter was projected to be an arc, forming a fan-shaped working zone, showed as direction $\mathrm{B}$ in Figure 7. Thus, the bionic included angle $\theta$ endowed the bionic cleaner with the motion functional morphology as the mole anterior claws, which facilitated to clean the straw residues in the strips.

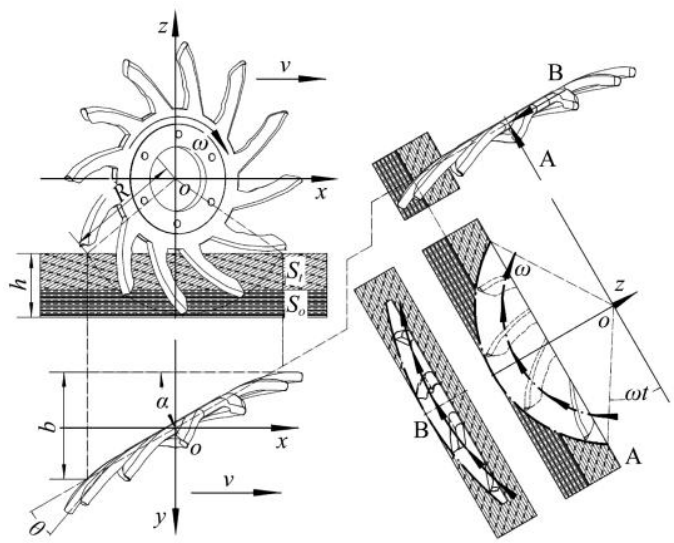

Note: $\mathrm{A}$ is the front view of the cleaner; $\mathrm{B}$ is the top view of the cleaner; $v$ is the forward speed, $\mathrm{m} / \mathrm{s} ; \omega$ is the rotational speed, $\mathrm{rad} / \mathrm{s} ; R$ is the radius of the cleaner, $\mathrm{mm} ; h$ is the effective working depth of the cleaner, $\mathrm{mm} ; \alpha$ is the installation angle, $\mathrm{rad} ; \theta$ is the bionic included angle, rad.

Figure 7 Motion analysis of a bionic cleaner

\subsubsection{Depth intelligent control system}

As shown in Figure 7, the working breadth of the bionic cleaning device can be calculated according to Equation (4).

$$
\begin{aligned}
W_{B}=2 b & =2\left(R+\sqrt{(R)^{2}-(R-h)^{2}}\right) \sin \alpha \\
& =2\left(R+\sqrt{2 R h-h^{2}}\right) \sin \alpha
\end{aligned}
$$

where, $W_{B}$ is the working breadth of the bionic cleaning device, $\mathrm{mm} ; b$ is the working breadth of a cleaner, $\mathrm{mm}$.

From Equation (4), when the deflection angle $\alpha$ and the disc radius $R$ were determined, the working breadth $W_{B}$ was only correlated with the working depth $h$. On this basis, a working depth intelligent control system was designed to ensure the stability of the working breadth of the bionic cleaning device and improve the consistency of seedling width.

The schematic diagram of the system was shown in Figure 8, it was mainly composed of control module, depth regulating device and pneumatic transmission actuator.

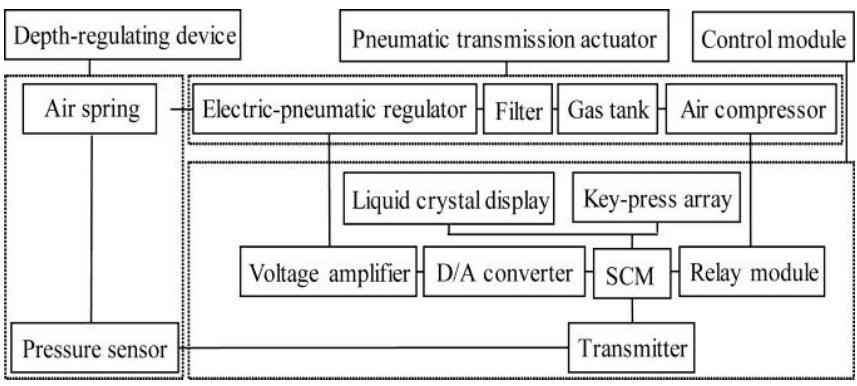

Figure 8 The schematic diagram of the depth intelligent control system 
The control module was used to set target depth value, collect and adjust the working depth of the bionic cleaning device in real time, which was composed of a STC89C52 single chip microcomputer (SCM), a D/A converter, a liquid crystal display and a key-press array. Figure 9 was the main schematic circuit diagram of control module. The key-press array contained four independent buttons for setting a target depth, which was connected to the I/O pins P1.0, P1.1, P1.2 and P1.3 of the MCU respectively. As mentioned above, the real-time depth of the bionic cleaning device could be measured by real-time monitoring the pressures from the S-shaped pressure sensor. And then, the SCM collected the real-time depth through Modbus bus (built by Max485 chip). According to the deviation between the real-time depth and the preset depth, the SCM drove the D/A converter through its I/O pin P0.4-P0.7 to output an analog control signal. After power amplification, the signal acted on the electric-pneumatic regulator to realize the adjustment of downforce provided by the air spring to the bionic cleaning device, so as to maintain the consistency of operating depth and ensured the stability of width.
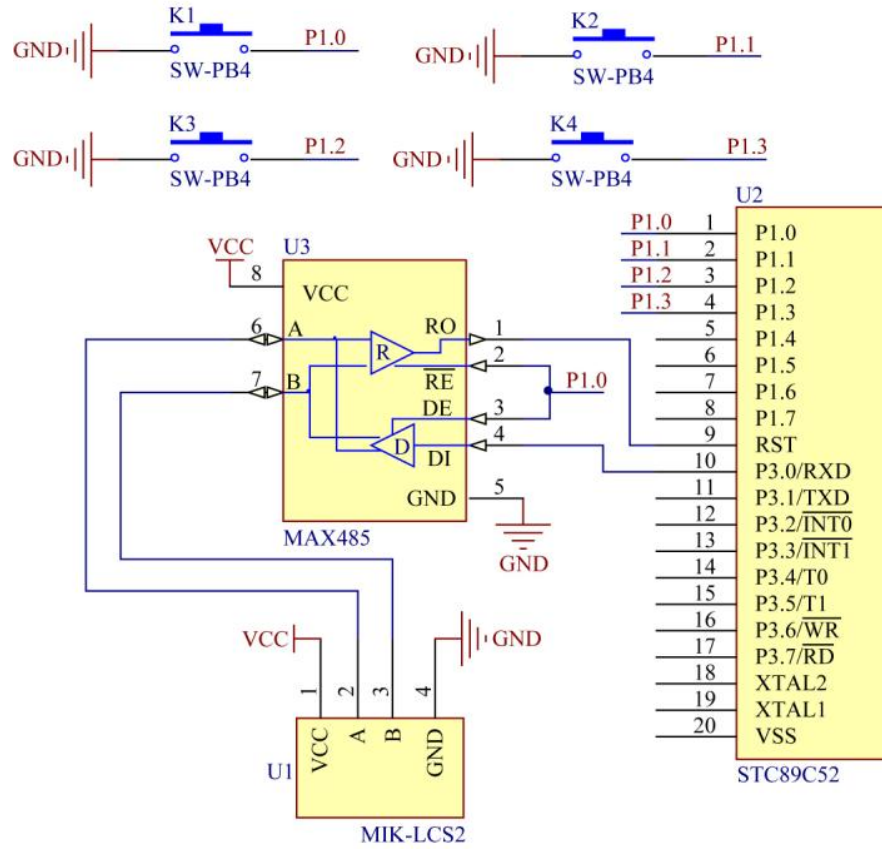

$\mathrm{P} 3.3 / \mathrm{INT}$
$\mathrm{P} 3.4 / \mathrm{T} 0$

$\mathrm{P} 3.4 / \mathrm{T} 0$
$\mathrm{P} 3.5 / \mathrm{T} 1$

$\mathrm{P} 3.6 / \overline{\mathrm{WR}}$

P3.7 $\overline{\text { RD }}$

XTAL2

19 XTAL

20 VSS

STC 89 C52

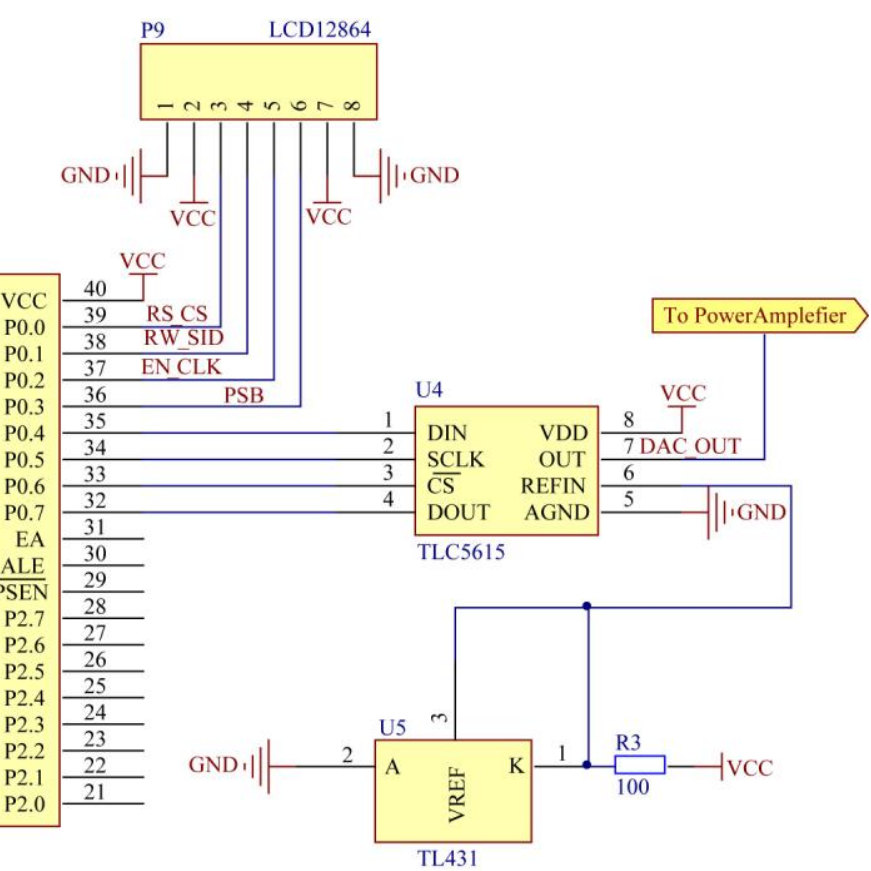

Figure 9 Schematic diagram of control module

The depth-regulating device was mainly composed of a S-shaped pressure sensor (MIK-LCS1, Meikong Automation Technology Co., Ltd., Hangzhou, China), and an air spring (1C3003, Guomat damping technology co. LTD, Guangzhou, China). The pressure sensor detected the pressure of the bionic cleaning device, the air spring supplied the downforce on the bionic cleaning device.

The pneumatic transmission actuator consisted of an air compressor, a gas storage tank, a filter, and an electric-pneumatic regulator. The compressed air was produced by the air compressor and stored in the storage tank. The electric-pneumatic regulator outputted stable pneumatic according to the control signals, and controlled the air spring to generate the corresponding downforce. The working depth intelligent control system was shown in Figure 10.

The system control flow was shown in Figure 11. When the system started to work, the internal resources (including I/O pins, registers, etc.) of the SCM were initialized firstly. Then, the system waited for the user to set the target depth value $H 0$ through the key-press array. After receiving the H0, the SCM got the real-time pressure value $P t$ detected by the S-shaped sensor and transformed the $P t$ into a real-time depth value $H t$. By comparing the deviation between $H 0$ and $H t$, MCU performed different operations. If $H t<H 0$, indicating that the cleaning device was not deep enough into the soil, the MCU calculated their deviation $\Delta H$, and converted $\Delta H$ into an analog signal by D/A converter to output.
After power amplification, the analog signal drove the electrical proportional valve for increasing the internal air pressure of the air spring. As the internal air pressure increased, the output downforce of the air spring also increased, forcing the claw teeth of the mechanism to go deep into the ground until the operating depth reached the preset target depth. For the case that $H t$ was not less than $H 0$, it indicated that the cleaning device was able to reach the preset target depth. In this case, the system did not perform any operation because the depth-limited adjustment plates would limit the occurrence of $\mathrm{Ht}$ greater than $\mathrm{HO}$.

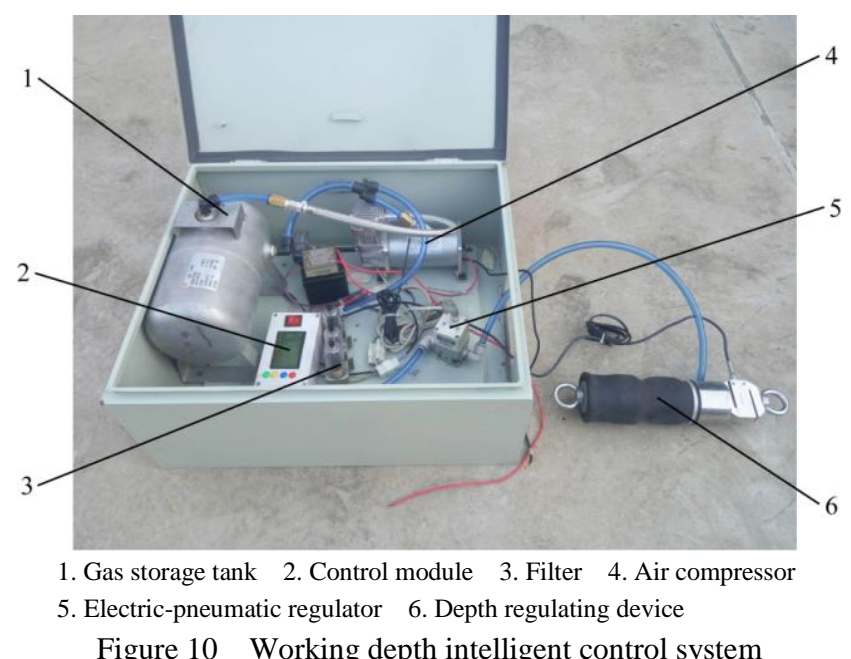

Figure 10 Working depth intelligent control system 


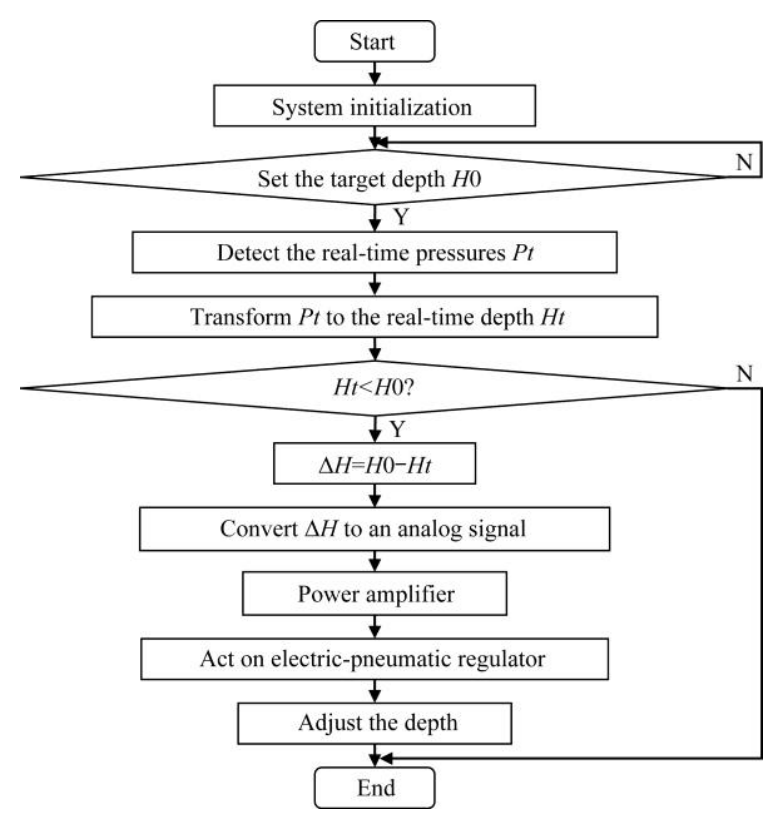

Figure 11 Control flow diagram of the depth intelligent control system

\subsection{Experimental method}

Discrete element method (DEM) and comparative field trial performance tests were combined. Structural design and parameter optimization of the bionic cleaners were conducted on the DEM simulation software EDEM. The working performances of the bionic cleaning device and the depth intelligent control system were validated and compared with the normal cleaning devices in field.

\subsubsection{Structural parameter optimization of bionic cleaner}

A cleaner-soil-straw interaction model was simulated for real soil conditions on EDEM software. The soil grain mechanical model was set as Hertz-Mindlin model with bonding; the straw grain mechanical model was set as Hertz-Mindlin glide-free contact model ${ }^{[20-22]}$. The global parameters were set as showed in Table 1.

Table 1 Setting of global parameters

\begin{tabular}{|c|c|c|}
\hline Item & Parameters & Value \\
\hline \multirow{3}{*}{ Soil particle } & Poisson' ratio & 0.38 \\
\hline & Shear modulus/Pa & $1 \times 10^{6}$ \\
\hline & Density $/ \mathrm{kg} \cdot \mathrm{m}^{-3}$ & 1850 \\
\hline \multirow{3}{*}{ Straw particle } & Poisson' ratio & 0.4 \\
\hline & Shear modulus/Pa & $1 \times 10^{6}$ \\
\hline & Density $/ \mathrm{kg} \cdot \mathrm{m}^{-3}$ & 241 \\
\hline \multirow{3}{*}{ Cleaner } & Poisson' ratio & 0.31 \\
\hline & Shear modulus/Pa & $7.8 \times 10^{10}$ \\
\hline & Density $/ \mathrm{kg} \cdot \mathrm{m}^{-3}$ & 7800 \\
\hline \multirow{3}{*}{ Soil - Soil } & Recovery coefficient & 0.6 \\
\hline & Static friction coefficient & 0.6 \\
\hline & Rolling friction coefficient & 0.4 \\
\hline \multirow{3}{*}{ Soil - Cleaner } & Recovery coefficient & 0.6 \\
\hline & Static friction coefficient & 0.3 \\
\hline & Rolling friction coefficient & 0.01 \\
\hline \multirow{3}{*}{ Straw - Cleaner } & Recovery coefficient & 0.3 \\
\hline & Static friction coefficient & 0.3 \\
\hline & Rolling friction coefficient & 0.01 \\
\hline
\end{tabular}

Soil and straw were modeled on EDEM ${ }^{20,23]}$ as particles size of 8-mm-diameter. According to the real sizes of shattered straws, a 90-mm-long linear model composed of eight 20-mm-diameter particles with inter-center space of $10 \mathrm{~mm}$ was used as the straw grain model. According to the actual working requirements of the cleaning device and the distribution of field straws, a virtual soil bin was built. The soil layer thickness was $50 \mathrm{~mm}$, the straw layer thickness was $40 \mathrm{~mm}$, the basic soil bin dimensions were $2000 \mathrm{~mm}$ in length, $650 \mathrm{~mm}$ in width and $90 \mathrm{~mm}$ in height. The simulation time was $10 \mathrm{~s}$. The simulation process is shown in Figure 12.

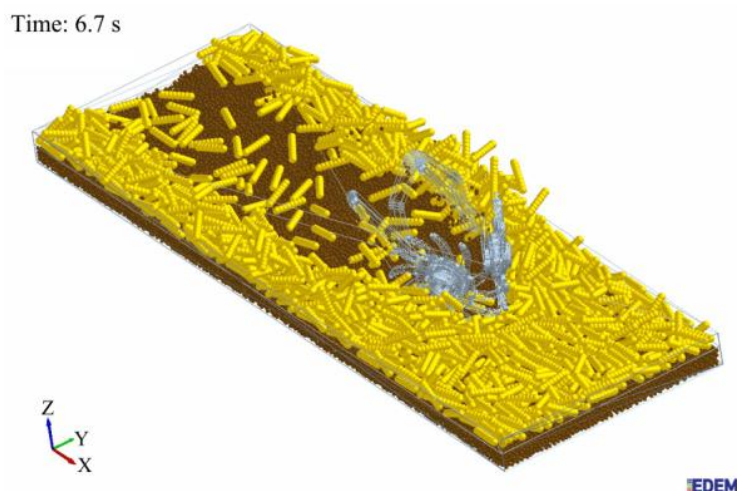

Figure 12 The virtual soil bin model

Tests consisted of two parts. First part, with the cleaner type as the test factor, being the straw cleaning rate $(\mathrm{C})$ and the working resistance of a cleaner $(\mathrm{R})$ as the test indices, it was thought that a higher cleaning rate and smaller working resistance indicated higher performance of the cleaners. During the tests, according to the actual conditions of no-tillage sowers, the forward speed of the cleaners were set at $2.22 \mathrm{~m} / \mathrm{s}$. The cleaner types were shown in Figure 13.

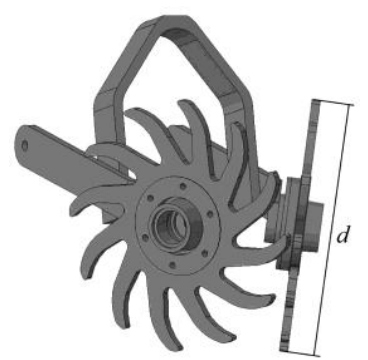

a . Cleaner without bionic elements (Normal cleaner)

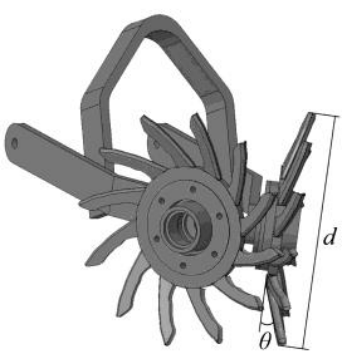

c. Cleaner with bionic included angle and bionic straight finger (Bionic cleaner-2)

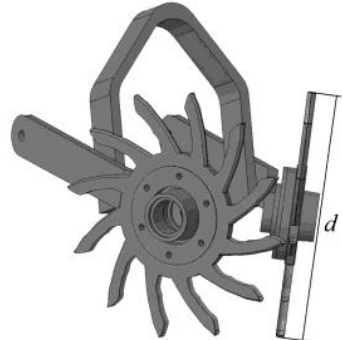

b. Cleaner with bionic straight finger (Bionic cleaner-1)

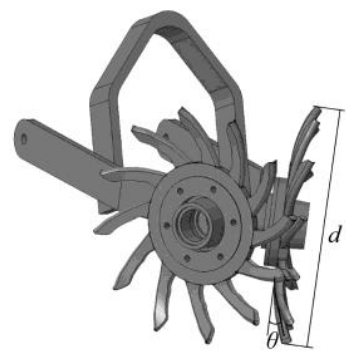

d. Cleaner with bionic included angle and bionic curved finger (Bionic cleaner-3)
Figure 13 The cleaner types

In the second part, orthogonal tests were conducted on basis of the previous virtual model and numerical simulation. The radius of gyration and the bionic included angle of bionic cleaners were considered as the test factors, and the straw cleaning rate and the working resistance of a cleaner were treated as indices. During the tests, according to the actual conditions of no-tillage sowers, the forward speed of the bionic cleaning device was set at $2.22 \mathrm{~m} / \mathrm{s}$. The levels of factors were set according to the single-factor preliminary test, and field strip cleaning requirements (Table 2). 
Table 2 Factors and levels of simulation experiments

\begin{tabular}{ccc}
\hline \multirow{2}{*}{ Levels } & \multicolumn{2}{c}{ Factors } \\
\cline { 2 - 3 } & Radius of gyration $A / \mathrm{mm}$ & Bionic included angle $B /\left(^{\circ}\right)$ \\
\hline 1 & 150 & 10 \\
2 & 165 & 15 \\
3 & 180 & 20 \\
\hline
\end{tabular}

\subsubsection{Comparative test of performance in field}

The tests were conducted in the agriculture machinery experiment field (coordinates $43.84^{\circ} \mathrm{N}, 125.33^{\circ} \mathrm{E}$ and altitude of $228 \mathrm{~m}$ ) of Jilin University, Changchun, Jilin province. Climate is continental in transition from a wet to semiarid zone with an annual average precipitation of $300-350 \mathrm{~mm}$ and an average summer temperature (June to August) of $15.2^{\circ} \mathrm{C}-23.1^{\circ} \mathrm{C}$. The soils in the fields belonged to typical black clay in Northeast China.

The field tests lasted from 3 to 5 May, 2017, with the daily average temperature of $12^{\circ} \mathrm{C}-16^{\circ} \mathrm{C}$ and no significant precipitation. Test plots were repeated with whole mulched straw shattering. A 2BMZ-2 maize no-tillage seeder equipped with pickup finger precision seed metering device was used and towed by a John Deere 504 tractor. The test equipment is shown in Figure 14. The soil physiochemical properties before tests are shown in Table 3.

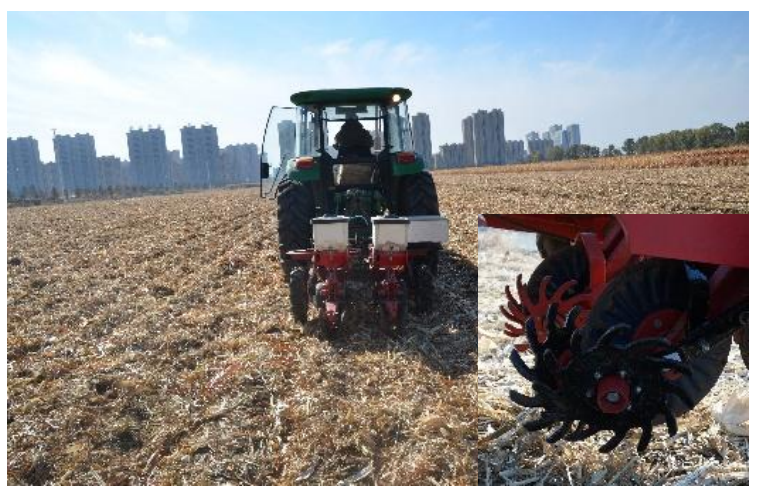

Figure 14 The 2BMZ-2 maize seeder with different row cleaners

Table 3 Some physical and chemical properties at soil depth 0-100 mm from the experimental site.

\begin{tabular}{lc}
\multicolumn{1}{c}{ Item } & Values \\
\hline Soil texture & clay \\
Cone index $/ \mathrm{MPa}$ & 0.985 \\
Bulk density $/\left(\mathrm{g} \cdot \mathrm{cm}^{-3}\right)$ & 1.189 \\
Soil moisture content $/ \%$ d.b. & 20.7 \\
Soil temperature $/{ }^{\circ} \mathrm{C}$ & 11.8 \\
Soil organic matter $/ \%$ & 3.65 \\
Total soil N/\% & 0.15 \\
$\mathrm{pH}$ & 7.19 \\
\hline
\end{tabular}

The strip length of each group of tests was $60 \mathrm{~m}$. The study was arranged in a randomized complete block designed as a $4 \times 3$ factorials with 12 treatments and three replications. The factor levels were the 4 types of cleaning devices: a bionic cleaner installed with the depth intelligent control system (A1), a normal cleaner installed with the depth intelligent control system (A2), a bionic cleaner (A2), and a normal cleaner (A4) as a control; the three forward speeds were $6 \mathrm{~km} / \mathrm{h}(\mathrm{V} 1), 8 \mathrm{~km} / \mathrm{h}(\mathrm{V} 2)$ and $10 \mathrm{~km} / \mathrm{h}$ (V3).

\subsection{Measurements}

2.3.1 Simulation index measurements

(1) Straw cleaning rate $(C)$
The number of straw particles in the test plot $(2 \mathrm{~m} \times 0.2 \mathrm{~m}$, frame in Figure 15) before and after the operation of the straw cleaning device was extracted by the solve report module of the software EDEM, and then the straw cleaning rate was calculated as follows:

$$
C=\left(1-\frac{S_{1}}{S}\right) \times 100 \%
$$

where, $C$ is the straw cleaning rate, $\% ; S_{1}$ is the number of straw particles after simulation test; $S$ is the number of straws before simulation test.

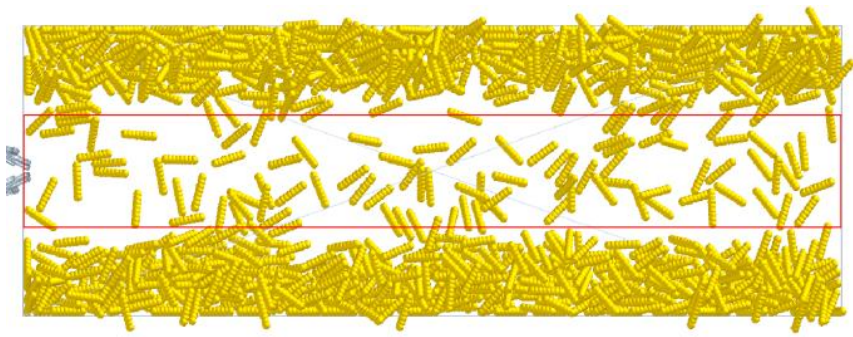

Figure 15 Sketch map of test zone of straw cleaning rate

(2) The working resistance of a cleaner $(R)$

With the Graph module from Analyst on EDEM, the real-time force data during the operation process were acquired (Figure 16). The average force under stable working condition was calculated on Excel.

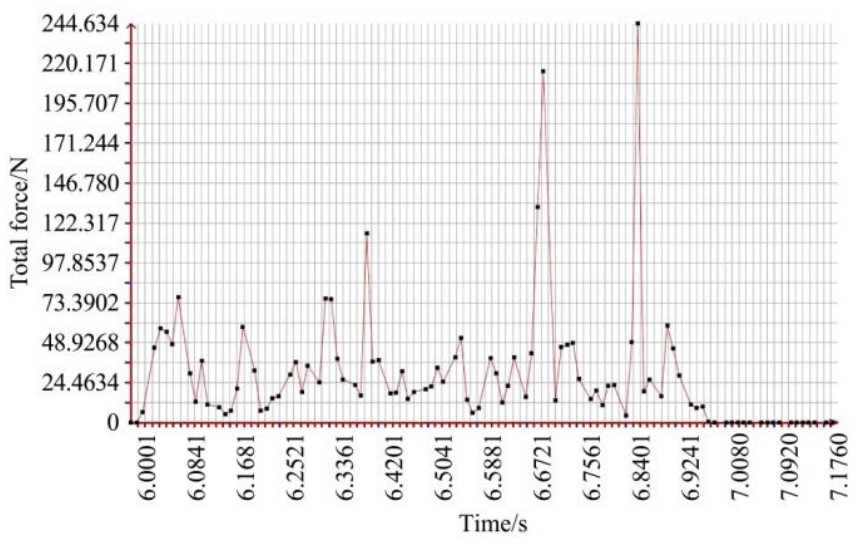

Figure 16 Force - time map of a clearner

\subsubsection{Straw cleaning rate of the field tests}

The amount of residue on the surface was measured prior to the tests. 5 test zones $(5 \mathrm{~m} \times 0.65 \mathrm{~m})$ were randomly selected within the sowing row (The row spacing of corn planting in Northeast China is $0.65 \mathrm{~m}$ ). Residue within the quadrat was collected. The residues were oven-dried at $55^{\circ} \mathrm{C}$ for $72 \mathrm{~h}$ and weighed ${ }^{[24]}$, in order to determine the dry mass of straw residues in the sowing row. The average value of the measurement results was taken as the unit mass of the residues before the tests, and was recorded as $\mathrm{M}$.

After each test, the residues mass of 3 test zones $(5 \mathrm{~m} \times 0.2 \mathrm{~m})$ was collected and weighed by the same method. The average value of the results was taken as the unit mass of the residues after the tests, and was recorded as $\mathrm{M}_{1}$. The straw cleaning rate in the field experiment was calculated as follows:

$$
C=\left(1-\frac{M_{1}}{M}\right) \times 100 \%
$$

where, $C$ is the straw cleaning rate, $\% ; M_{1}$ is the unit mass of the residues after the tests; $M$ is the unit mass of the residues before the tests. 


\section{Results and analysis}

\subsection{Cleaner types simulation}

The cleaner types significantly affected both the straw cleaning rate and working resistance $(p<0.05)$.

As shown in Figure 17 and 18, Bionic cleaners-2 and especially Bionic cleaners- 3 possessing included angles $\theta$ had higher straw cleaning rates than the planar cleaner. Compared with the Normal cleaner, the straw cleaning rate of Bionic cleaner-2 and Bionic cleaner-3 were $11.2 \%$ and $13.9 \%$ higher, respectively; but that of Bionic cleaner-1 was reduced by $2.5 \%$. Bionic cleaners 3 and especially 2 possessing included angles $\theta$ suffered lower working resistance than the planar cleaner. Compared with the Normal cleaner, the working resistances of Bionic cleaners- 1,2 and 3 reduced by $35.2 \%, 49.4 \%$ and $48.3 \%$, respectively.

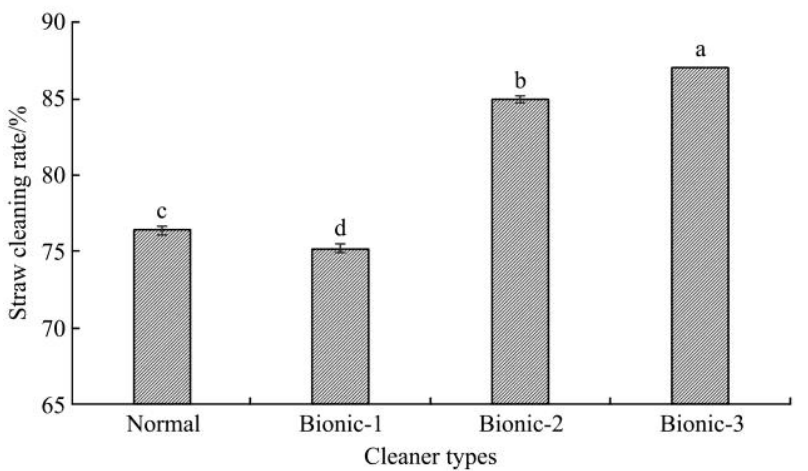

Figure 17 Effects of cleaner types on straw cleaning rate

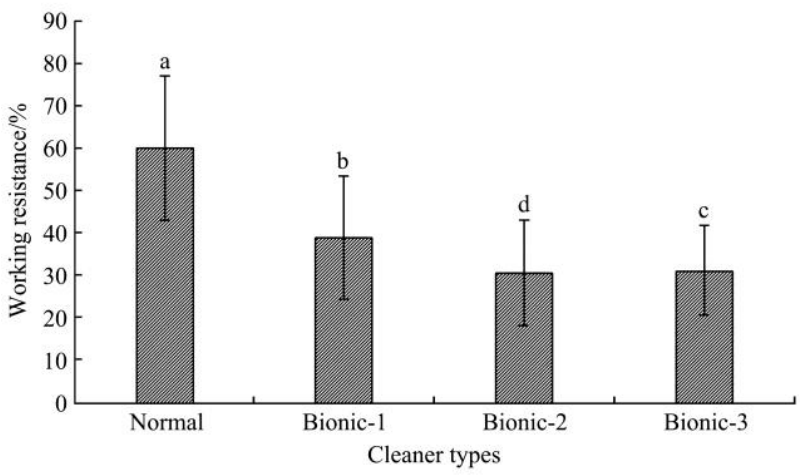

Figure 18 Effects of cleaner types on working resistance

The straw cleaning rate was not largely affected by only changing the contour of the fingers, but the working resistance was significantly reduced, as that of Bionic cleaner-1 was only $64.8 \%$ that of the Normal cleaner. By changing the contours of fingers and increasing the bionic angle $\theta$ simultaneously, the increase of straw cleaning rate and the significant reduction of working resistance were achieved at the same time. The straw cleaning rates of Bionic cleaners 2 and 3 were 1.11 and 1.14 times that of the Normal cleaner, respectively, but the working resistances were only $50.6 \%$ and $51.7 \%$ that of the Normal cleaner, respectively.

Given the effects of cleaner types on straw cleaning rate and working resistance, we selected bionic cleaner-3 in the subsequent structural optimization.

\subsection{Structural parameter optimization of bionic cleaner-3}

Simulation plan of 3-level full factorial tests was adopted, and the results were listed in Table 4.

The significance of data was tested to accurately judge the effects of different factor levels on the straw cleaning rate and working resistance (Table 5). Clearly, both radius of gyration and the bionic included angle were interactive and significantly affected the straw cleaning rates and working resistance.

Table 4 Test plan and results

\begin{tabular}{cccccc}
\hline & \multicolumn{3}{c}{ Factors } & & \multicolumn{2}{c}{ Test evaluation indexes } \\
\cline { 2 - 4 } \cline { 4 - 5 } 1 & $\mathrm{~A}$ & $\mathrm{~B}$ & $\mathrm{C} / \%$ & $\mathrm{R} / \mathrm{N}$ \\
\hline 2 & $-1(150)$ & $-1\left(10^{\circ}\right)$ & 86.4 & 29.1 \\
3 & $0(165)$ & -1 & 82.8 & 34.1 \\
4 & $1(180)$ & -1 & 80.7 & 42.9 \\
5 & -1 & $0\left(15^{\circ}\right)$ & 91.3 & 29.7 \\
6 & 0 & 0 & 88.3 & 35.6 \\
7 & 1 & 0 & 87.7 & 44.7 \\
8 & -1 & $1\left(20^{\circ}\right)$ & 92.3 & 31.1 \\
9 & 0 & 1 & 91.2 & 37.9 \\
10 & 1 & 1 & 90.4 & 47.5 \\
11 & 0 & 0 & 88.7 & 35.1 \\
12 & 0 & 0 & 90.3 & 35.3 \\
13 & 0 & 0 & 88.8 & 35.9 \\
\hline
\end{tabular}

Table 5 Significance analysis of different factors on performance indices

\begin{tabular}{ccc}
\hline \multirow{2}{*}{ Text index } & \multicolumn{2}{c}{ Significance } \\
\cline { 2 - 3 } & $\mathrm{C}$ & $\mathrm{R}$ \\
\hline $\mathrm{A}$ & $<0.001^{* * * *}$ & $<0.001^{* * *}$ \\
$\mathrm{~B}$ & $<0.001^{* * *}$ & $<0.001^{* * *}$ \\
$\mathrm{~A} 2$ & 0.224 & $<0.001^{* * *}$ \\
$\mathrm{~B} 2$ & $0.001^{* * *}$ & $0.016^{* *}$ \\
$\mathrm{~A} * \mathrm{~B}$ & $0.015^{* *}$ & $0.002^{* * *}$
\end{tabular}

Note: *: a bit significant $(p<0.10)$; $* *$ : significant $(p<0.05)$; ***: very significant $(p<0.01)$.

The two performance indices were fitted by regression equations according to the analysis of variance in Table 5. After the factors with insignificant effects were ignored, the regression equation involved, the significant factors is as follows:

$$
\begin{gathered}
Y_{1}=89.01-1.87 A+4.00 B+0.95 A B-2.02 B^{2} \\
Y_{2}=35.44+7.53 A+1.73 B+0.65 A B+1.72 A^{2}+0.52 B^{2}
\end{gathered}
$$

where, $Y_{1}$ is the straw cleaning rate; $Y_{2}$ is the working resistance.

The response surface method (RSM) curves showing the effects of the radius of gyration and bionic included angle on straw cleaning rate and working resistance were determined on Design-Expert 8.0 (Figure 19). Analyses showed the bionic included angle more significantly affected the straw cleaning rates. The cleaning rate was negatively correlated with the radius of gyration, but positively correlated with the bionic included angle. The radius of gyration was more significantly affected by the working resistance, which was enlarged with the increase of radius of gyration or bionic included angle.

According to the test results and fitted regression equations, the structural parameters of the bionic cleaner- 3 were optimized on Design-Expert 8.0, following the objectives to increase the straw cleaning rate and reduce the working resistance. By comprehensively analyzing the working requirements of bionic cleaning devices, the optimal parameter combination obtained to be radius of gyration $=150 \mathrm{~mm}$, bionic included angle $=15.8^{\circ}$, and the corresponding straw cleaning rate in the simulation tests was $91.3 \%$ and the working resistance was $30.32 \mathrm{~N}$. 


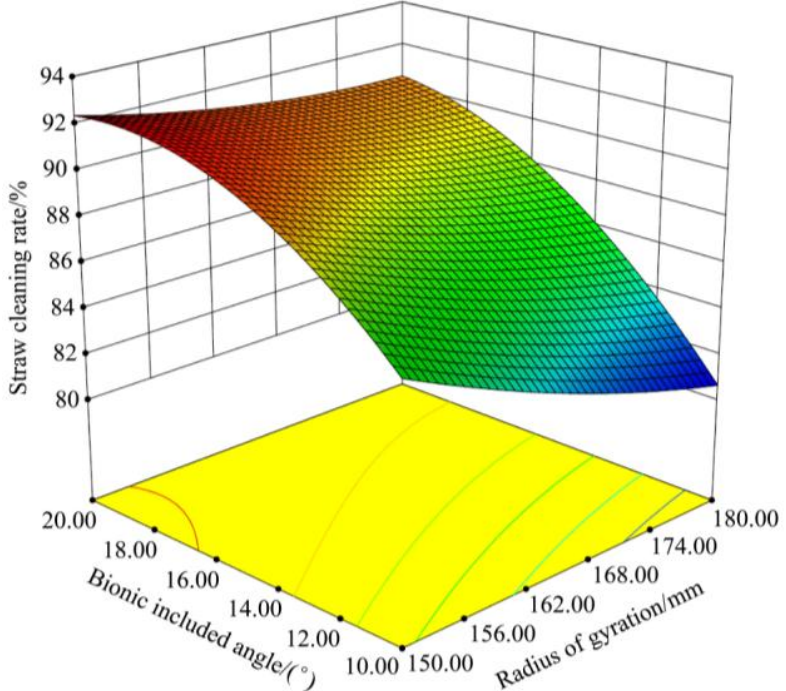

a. Straw cleaning rate versus radius of gyration and bionic angle

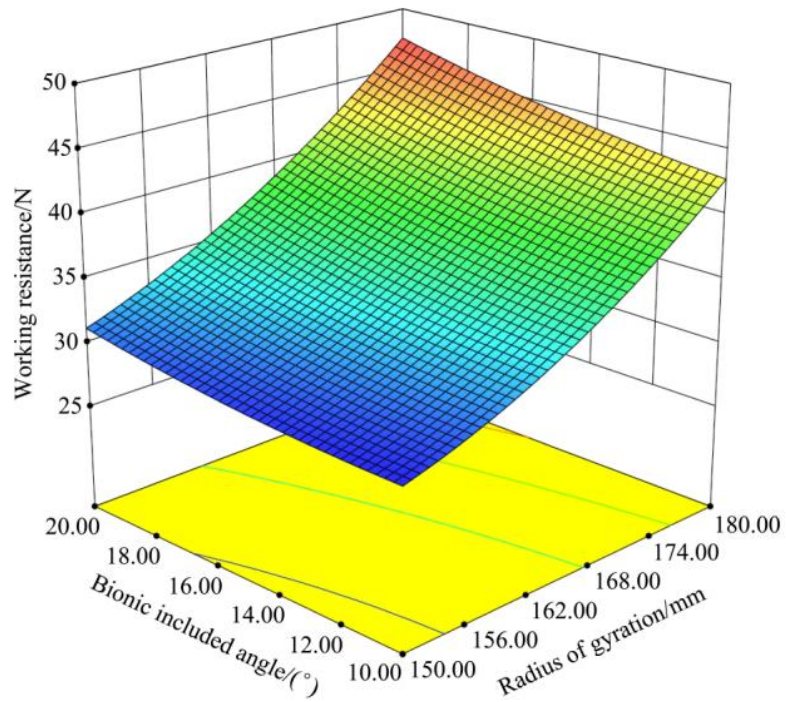

b. Working resistance versus radius of gyration and bionic angle Figure 19 RSM curves

\subsection{Results and analysis of the field tests}

The average straw residues in the test plots were $7250 \mathrm{~kg} / \mathrm{ha}$, and the structural parameters of bionic cleaners during the tests were radius of gyration $=150 \mathrm{~mm}$ and bionic included angle $=16^{\circ}$.

Figure 20 shows the effects of different factors on the straw cleaning rates. Both, cleaner types and forward speeds significantly affected the straw cleaning rate $(p<0.05)$.

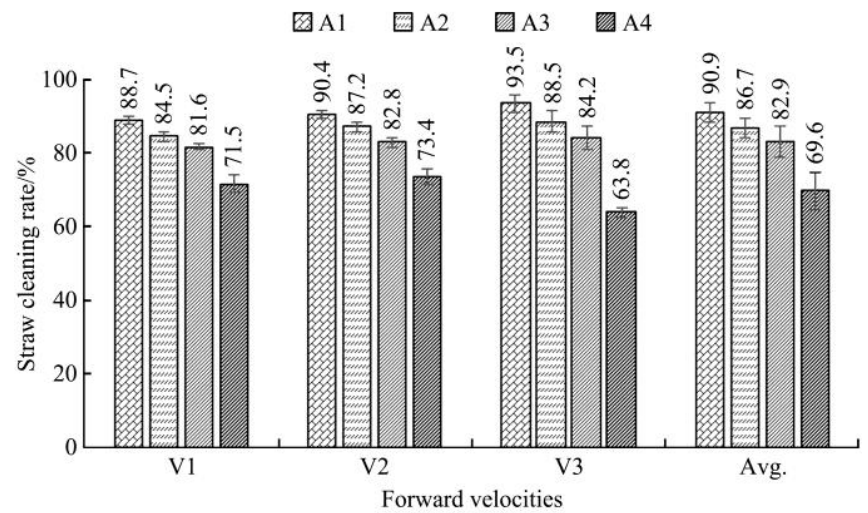

Figure 20 Effects on different factors on straw cleaning rates

Under the same forward speed, the straw cleaning rate always maximized in A1 and minimized in A4. In terms of averages, the straw cleaning rates of treatments $\mathrm{A} 1, \mathrm{~A} 2$ and $\mathrm{A} 3$ were $21.3 \%$,
$17.1 \%$ and $13.3 \%$ higher than $\mathrm{A} 4$, respectively. The test group with the bionic cleaning device and the test group with the depth intelligent control system both showed higher straw cleaning rates than the control group, while A1 installed with both showed the best working performance. In addition, the depth intelligent control system was more effective on the normal cleaning device than on the bionic cleaning device, as the straw cleaning rates increase by $17.1 \%$ and $8.0 \%$, respectively.

The above results indicate the bionic intelligent cleaning row cleaner can more effectively work under the condition of whole straw shattering return. The cleaning effects after the work of the sowers are shown in Figure 21.

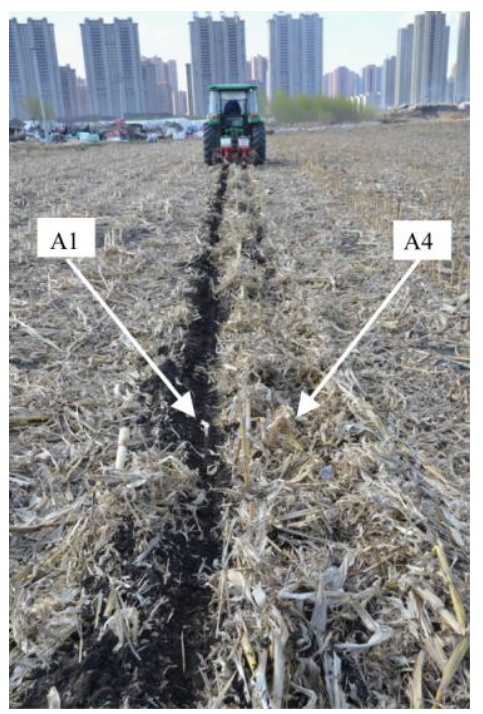

Figure 21 Comparison of working effects with difference row cleaners

\section{Conclusions}

1) Bionic cleaners based on the forelimb motion morphology and front claw toe structural morphology of moles were designed. The special structure of bionic included angle enhanced the passive rotation torque under the same working depth, and enlarged the throwing force acting on the straw residues, thereby increasing the straw cleaning rate by $13.3 \%$.

2) A set of working depth intelligent control system was designed. The S-shaped pressure sensor was used as the soil insertion pressure detection unit of the cleaning devices. According to the output signals from the sensor, the pneumatic transmission actuator was real-time controlled to adjust the downforce of the air spring on the cleaning device, which further stabilized the working depth. Moreover, the straw cleaning rates of bionic cleaning device and normal planar cleaner device rose by $8.0 \%$ and $17.1 \%$, respectively.

3) Simulations on EDEM showed the radius of gyration and bionic included angle both significantly affected both straw cleaning rate and working resistance, were interactive for both indices. Regression revealed the optimal parameter combination: radius of gyration $=150 \mathrm{~mm}$ and bionic included angle $=15.8^{\circ}$, at which the straw cleaning rate was $91.3 \%$ and the working resistance was $30.32 \mathrm{~N}$. Field tests suggest compared with the normal planar cleaner, the bionic mole forelimb intelligent row cleaners increased the straw cleaning rate by $21.3 \%$ and can efficiently clean the plots with whole straw return, which satisfy the requirements of no-tillage sowers. This study is significant for improving the maize planting quality in Northeast China. 


\section{Acknowledgements}

This work was financially supported by the National Key R \& D Plan project (Grant No. 2016YFD070030201) and the Jilin Science and Technology Development Plan (20160309001NY). The authors highly appreciate Yongiian Cong who is the teacher of School of Biological and Agricultural Engineering, Jilin University for his assistance on field measurements.

\section{[References]}

[1] Jia H L, Ma C L, Li H Z, Chen Z L. Tillage soil protection of black soil zone in northeast of China based on analysis of conservation tillage in the United States. Transactions of the CSAM, 2010; 41(10): 28-34. (in Chinese)

[2] Zhang S X, Li Q, Lv Y, Sun X M, Jia S X, Zhang X P, Liang W J. Conservation tillage positively influences the microflora and microfauna in the black soil of Northeast China. Soil \& Tillage Research, 2015; 149: 46-52.

[3] Chastin T G, Ward K J, Wysocki D J. Stand establishment response of soft whiter wheat to seedbed residue and seed size. Crop Science, 1995; 35(1): 213-218

[4] Ministry of Agriculture. Agricultural mechanization management. conservation tillage in China. Beijing: China Agricultural Publishing House, 2008.

[5] Zhao J L, Jia H L, Guo M Z, Jiang X M, Qu W J, Wang G. Design and experiment of supported roll-cutting anti-blocking mechanism with for no-till planter. Transactions of the CSAE, 2014; 30(10): 18-28. (in Chinese)

[6] Zhao J L, Huang D Y, Jia H L, Zhuang J, Guo M Z. Analysis and experiment on cutting performances of high-stubble maize stalks. Int $\mathrm{J}$ Agric \& Biol Eng, 2017; 10(1): 40-52.

[7] He J, Li H W, Chen H T, Lu C Y, Wang Q J. Research progress of conservation tillage technology and machine. Transactions of the CSAM, 2018; 49(4): 1-19.

[8] Morris N L, Miller P C H, Orson J H, Froud-Williams R J. The adoption of non-inversion tillage systems in the United Kingdom and the agronomic impact on soil, crops and environment-a review. Soil Tillage Res., 2010; 108: 1-15.

[9] Siemens M C, Wilkins D E, Correa R F. Development and evaluation of a residue management wheel for hoe-type no till drills. Trans. Am. Soc. Agric. Eng., 2004; 47(2): 397-404.

[10] Liao Q X, Gao H W, Shu C X. Present situations and prospects of anti-blocking technology of no-tillage planter. Transactions of the CSAE, 2004; 20(1): 108 - 112. (in Chinese)

[11] Gao H W, Li W Y. Conservation tillage techniques and implements. BeiJing: Chemical Industry Press, 2004.

[12] Raoufat M H, Matbooei A. Row cleaners enhance reduced tillage planting of corn in Iran. Soil \& Tillage Research, 2007; 93(1): 152-161.

[13] Fallahi S, Raoufat M H. Row-crop planter attachments in a conservation tillage system: A comparative study. Soil and Tillage Research, 2008; 98(1): 27-34.

[14] Fan X H, Jia H L, Zhang W H, Yang H T, Gu Y Q, Li H G. Parametric analysis of finger-type anti-blocking residue-cleaner for no-till planting. Transactions of the CSAM, 2011; 42(10): 56-60. (in Chinese)

[15] Lin J, Li B F, Li H Z. Design and experiment of archimedes spiral type stubble breaking ditching device and stubble breaking anti blocking device. Transactions of the CSAE, 2015; 31(17): 10-19. (in Chinese)

[16] Ren L Q. Introduction to Bionics. Beijing: Science Press, 2016

[17] Liu C Y. Cutting mechanism of claws of the mole-rat (Scaptochirus moschatus). Doctoral dissertation, Jilin University, China, 2008. (in Chinese).

[18] Scott R G, Richardson R C. Realities of biologically inspired design with a subterranean digging robot example. Proceedings of the 6th IASTED International Conference on Robotics and Applications. Cambridge, MA, USA, 2005; pp.226-231.

[19] Ji W F, Tong J, Jia H L. Quantitative characteristic features of geometric structures of claws of mole rat. Transactions of the CSAM, 2010; 41(4): 193-198. (in Chinese)

[20] Fang H M. Research on the straw-soil-rotary blade interaction using discrete element method. Doctoral dissertation, Nanjing Agricultural University, China, 2016. (in Chinese).

[21] Mak J, Chen Y, Sadek M A. Determining parameters of a discrete element model for soil-tool interaction. Soil \& Tillage Research, 2012; 118: 117-122

[22] Chen Y, Lars J M, Tavs N. A discrete element model for soil-weep interaction in three different soils. Soil \& Tillage Research, 2013; 126 : 34-41.

[23] Wang J W, Tang H, Wang J F, Huang H N, Lin N N, Zhao Y. Numerical analysis and performance optimization experiment on hanging unilateral ridger for paddy field. Transactions of the CSAM, 2017; 48(8): 72-80. (in Chinese)

[24] Yang L, Zhang R, Gao N N, Cui T, Liu Q W, Zhang D X. Performance of no-till corn precision planter equipped with row cleaners. Int J Agric \& Biol Eng, 2015; 8(5): 15-25. 